\title{
SEISMIC VULNERABILITY ASSESSMENT OF REPRESENTATIVE BUILDING TYPOLOGIES FROM BARCELONA'S EIXAMPLE DISTRICT
}

\author{
SARA DIMOVSKA ${ }^{1 *}$, SAVVAS SALOUSTROS ${ }^{1}$, LUCA PELÀ $^{1}$ \\ AND PERE ROCA ${ }^{1}$ \\ ${ }^{1}$ Universitat Politècnica de Catalunya (UPC-BarcelonaTech) \\ Jordi Girona 1-3, 08034 Barcelona, Spain \\ e-mails: sara.dimovska@upc.edu*, savvas.saloustros@upc.edu, luca.pela@upc.edu, \\ pere.roca.fabregat@upc.edu
}

Keywords: Seismic Vulnerability, Masonry, Building Taxonomy, Pushover analysis

\begin{abstract}
Unreinforced masonry buildings prevail in many old historical centres and urban areas worldwide. These structures may present inadequate seismic performance because they were often designed without considering any seismic resistance requirements. Therefore, they may be highly vulnerable and susceptible to damage caused by earthquakes, even of low intensity.

This work investigates the seismic vulnerability of typical unreinforced masonry buildings situated in the Eixample district of Barcelona, Spain. Most of the buildings of the district were designed only for vertical static loads with slender load-bearing masonry walls and flexible diaphragms. A typical characteristic is the presence of openings with considerable size on the facades. The identification of the main parameters affecting the structural behaviour under lateral loading is necessary to evaluate the seismic vulnerability.

As a first step, a building taxonomy for the Eixample district has been prepared in order to classify the different building typologies by taking into account the influence of the structural features in the overall response. This typology classification serves two aims. The first aim is to empirically evaluate the vulnerability of each category. The second one is to provide the basis for creating a numerical model of a representative building and analyse its seismic performance.

The main objective of this paper is to assess the seismic behaviour of a typical unreinforced masonry structure by means of nonlinear static analysis. For this purpose, a three-dimensional Finite Element model of a representative building has been prepared. Pushover analyses have been performed in two directions (parallel and perpendicular to the façades) aiming to identify the typical failure mechanisms and the seismic capacity.

The performance of the representative building typology, with its typical heterogeneities and irregularities, is compared with that of a reference regular unreinforced masonry structure. Additionally, a parametric analysis is carried out to evaluate the different seismic response by adding more storeys in height. This work is the basis for future analyses devoted to large scale seismic vulnerability assessment of the most representative building typologies of the Eixample district.
\end{abstract}




\section{INTRODUCTION}

Unreinforced masonry buildings prevail in many old historical centres and urban areas worldwide. A large number of these buildings present an unquestionable cultural and architectural value due to their significant contribution to the urban landscape [1]. In several cases, these structures mainly consist of load-bearing walls made of brick or stone masonry. Often, masonry buildings were designed without considering seismic requirements and may be highly vulnerable against seismic actions even in a region with moderate seismic hazard.

In the last years, there has been an increasing interest in the study of seismic risk in urban areas, which has resulted in various seismic risk assessment methodologies. The choice of the appropriate approach depends on several factors, including the nature of the problem and the purpose of the study. Different methods of assessment are currently available in the scientific literature based on empirical, analytical or hybrid procedures. Empirical methods, also known as indirect methods, are less accurate but more affordable for large scale assessments [2]. On the contrary, analytical (direct) methods require sophisticated structural analyses, based for instance in the Finite Element Method. The hybrid procedure is a combination of both indirect and direct methods.

In this work, the analytical method is used to analyse and understand the seismic performance of a typical unreinforced masonry building. By doing so, this study aims to identify the critical features of their seismic performance and to estimate the likely damage that may be produced due to the seismic action.

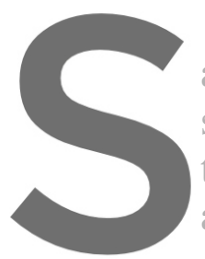

As a first step, a buil

a representative structure structures according to taxonomy has assistec as and structure to be consid
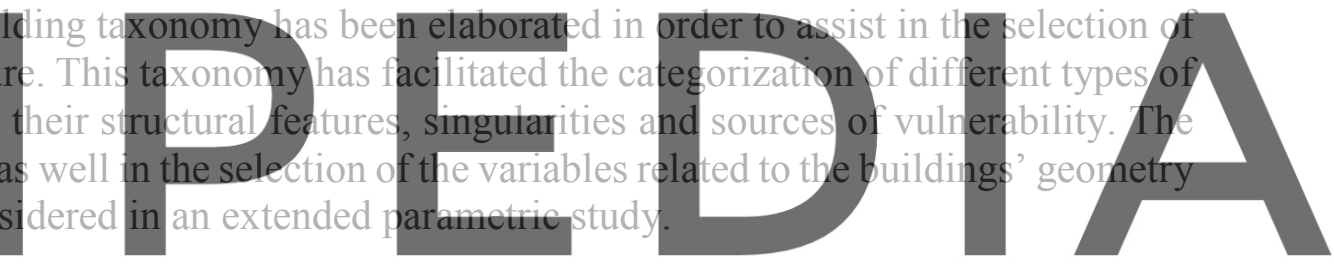

2 CASE STUDY - EIXAMIPLE DISTRICT OF BARCELONA

Register for free at https//www.scipedia.com to download the version without the watermark The focus of the present study is the evaluation of the seismic vulnerability of a typical building typology located in the Eixample district of Barcelona.

The urban area of Eixample is characterized by its straight avenues, laid out in a grid in the central part of the city (Figure 1). Built during the 19th and the beginning of the 20th century, this district stands out for its architectural and cultural heritage. Most of the buildings were constructed as unreinforced masonry ones, forming aggregates that comprise typical building blocks, so-called "manzanas" in Spanish [3]. Each block is composed of rectangular buildings along the streets and pentagonal building at the chamfered corners. The structures that typify the district remain in use today, mainly unaltered since their construction. The peculiar structural systems of unreinforced masonry bearing walls were designed for gravitational loads only, without considering any seismic design criteria. Therefore, these typologies may be highly vulnerable under horizontal actions, even though the seismic hazard in this region is low to moderate. 


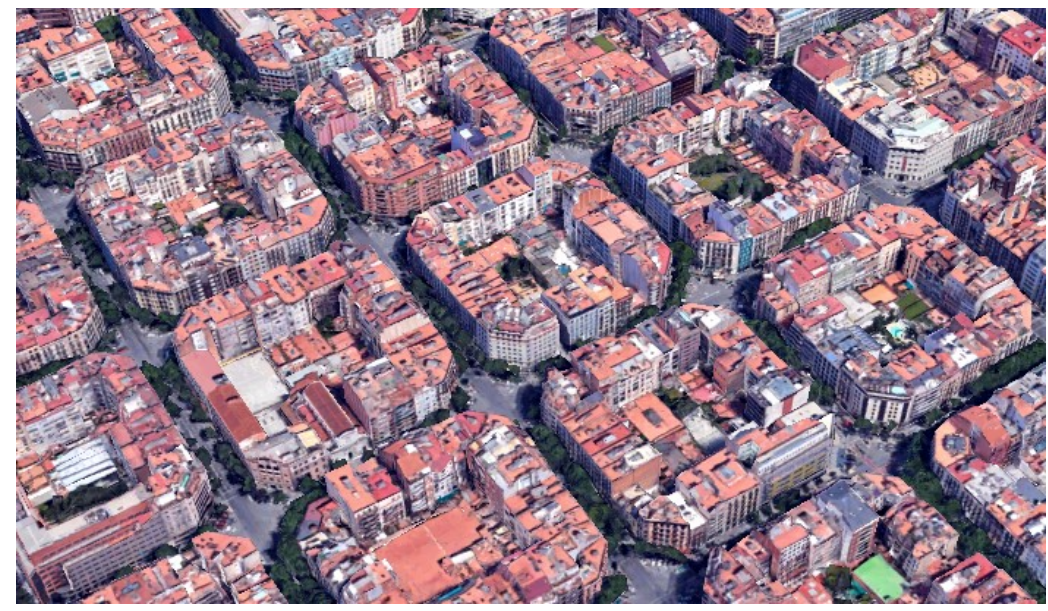

Fioure 1: View of Eixamnle district

Recent studies [5] [6] have confirmed the high seismic vulnerability of the unreinforced masonry buildings of Barcelona and highlighted the need for the assessment of each building's seismic demand and performance. The current study uses a different analysis tool to that of the previous ones, i.e. a 3D finite element analysis. This approach considers the global response of the structure, helping to obtain a better understanding of the seismic capacity and vulnerability of the unreinforced masonry buildings

The first step has been to of the building typologies ac

seismic vulnerability

3 BUHLDING TAXONOMY
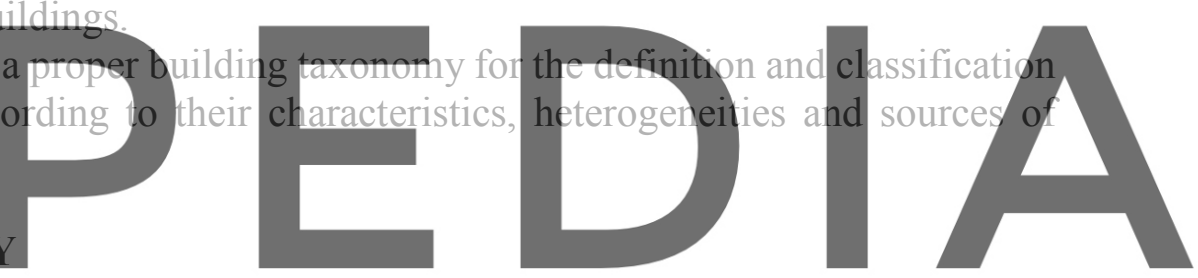

The building taxonomy describes the characteristics of an individual building or a class of

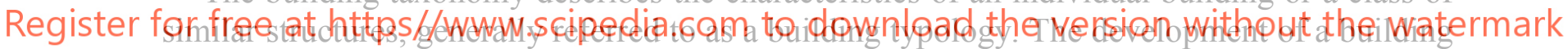

taxonomy of existing buildings is essential to understand their structural and architectural configuration relevant to their seismic behaviour. This typology classification has assisted to empirically evaluate the buildings' vulnerability and also to provide the basis for creating a numerical model of a representative building for analysing its seismic performance.

The division of the building stock in a city or a region is among the main challenges for carrying out a seismic risk assessment at urban scale. The primary purpose of a building taxonomy is to classify and group building typologies that show comparable overall performance during a seismic action. Therefore, it is necessary to classify buildings by referring to some parameters that describe a specific characteristic, affecting the seismic behaviour of an individual building or a group of buildings. Geometry, material properties, lateral load resisting system, construction date, seismic design level, structural irregularities, foundation details are among the usual typology parameters that are considered for a building taxonomy. The main features influencing the structural vulnerability are the building's load resisting system and the used construction materials. Secondary classification parameters may be the overall building height, period of construction, shape of the building plan, foundation, irregularities, etc. The 
flow chart of Figure 2 presents all the parameters considered in the building taxonomy of the Eixample district.

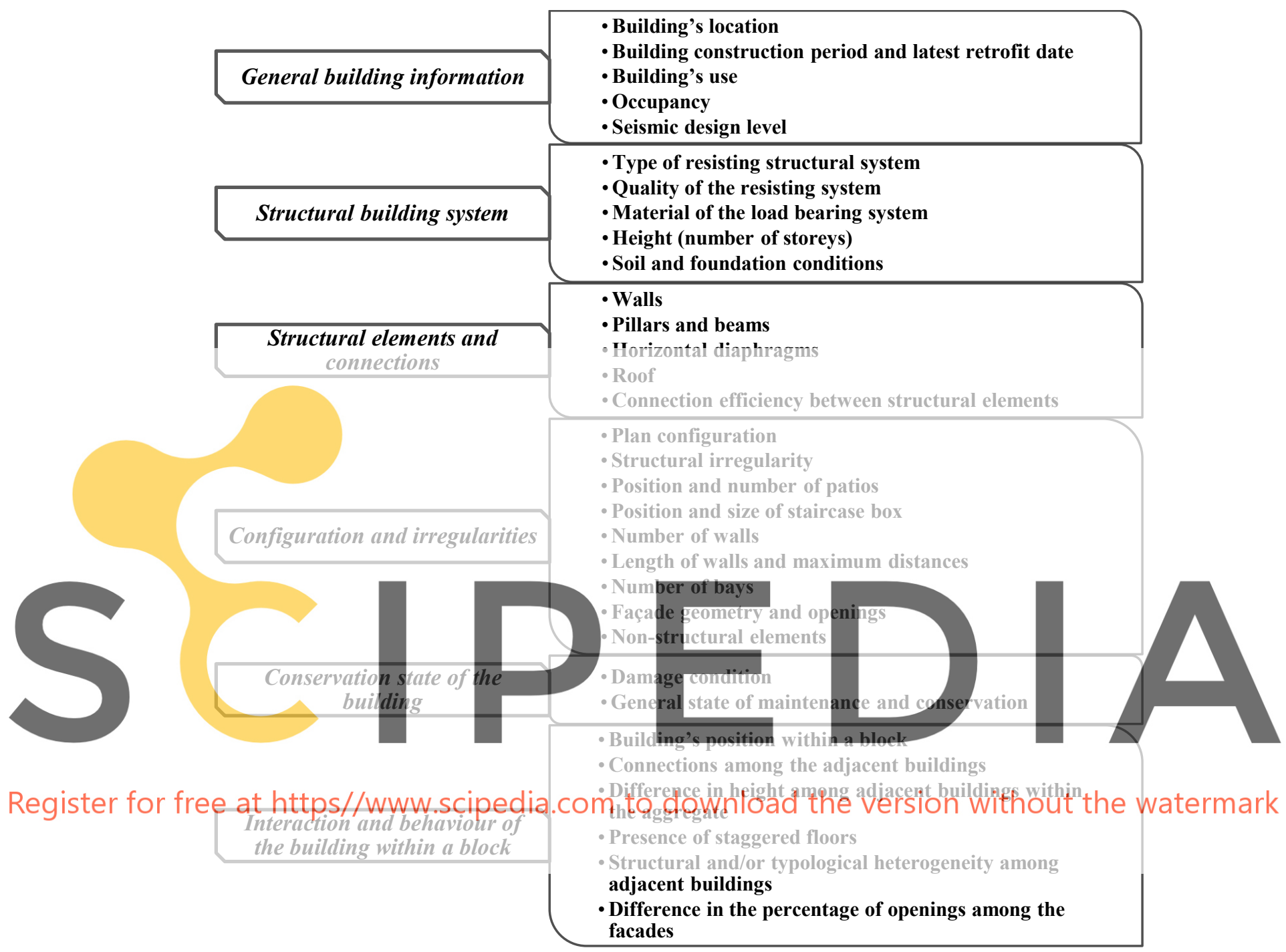

Figure 2: Parameters for a specified building taxonomy

The building taxonomy has been prepared for the purpose of classifying the different structural typologies and selecting some representative buildings for the seismic vulnerability assessment by means of numerical methods. Accordingly, the building classification has been done by taking into account the influence of the most important characteristics in the buildings' seismic performance.

The construction of the buildings was carried out between 1860 and 1940, with an average of 25 buildings per block (Figure 3). Nearly $70 \%$ of the buildings of Eixample are unreinforced masonry ones, designed without considering any seismic requirements [5]. From the '60s, reinforced concrete structures were built, leading to the beginning of contemporary architecture [3]. 


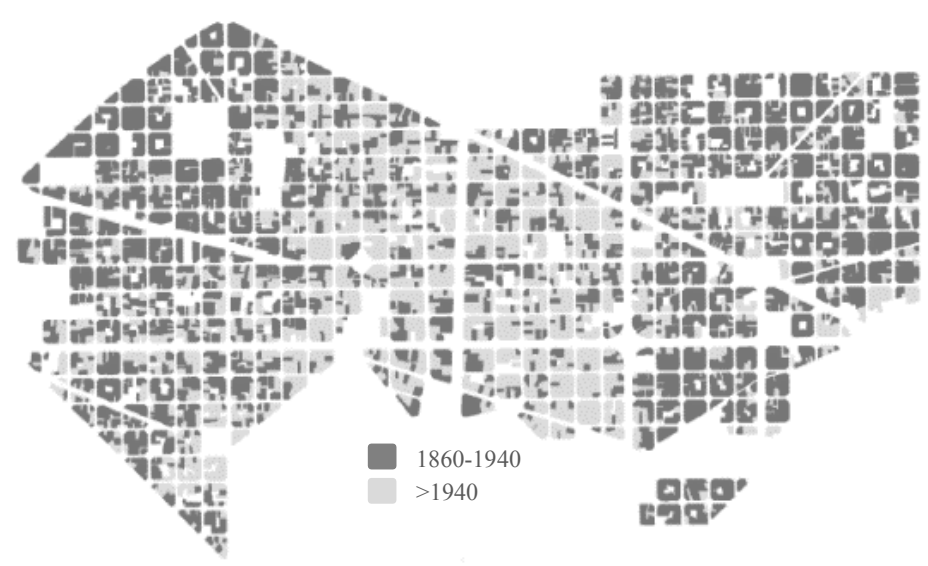

Figure 3: Construction period of Eixample district [6]

Eixample buildings can be categorised in the following typologies (Figure 4): one with loadbearing masonry walls throughout the full height and a second one with a hybrid structural system of steel/concrete columns on the ground floor and unreinforced masonry walls on the upper ones. The floor system is mostly flexible, made of timber or steel beams connected with tile barrel vaults. However, due to some rehabilitations, rigid reinforced concrete slabs can be

found in some structures.

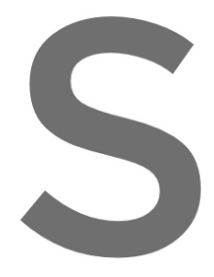

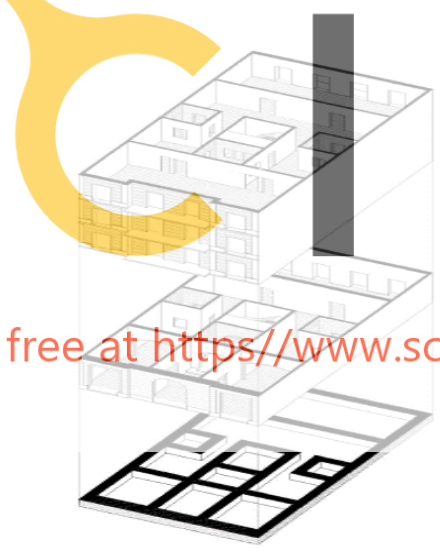

a)
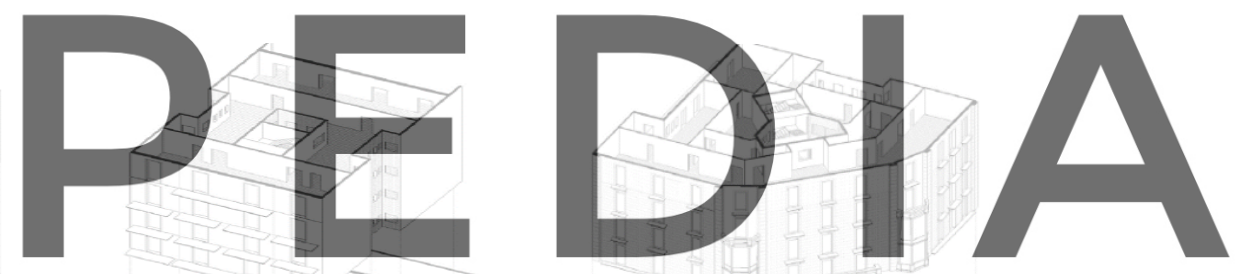

Register for free at https//Wwww.scipedia.com to download the version without the watermark

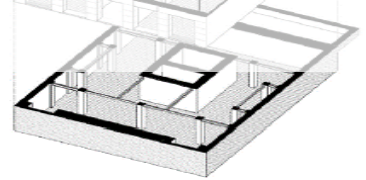

b)

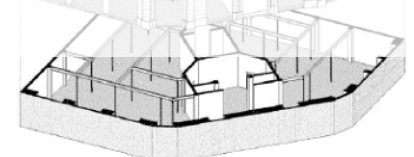

c)

Figure 4: Different structural systems [3]: a) homogenous system of slender walls; b) hybrid system - concrete columns and masonry walls; c) hybrid system - steel columns and masonry walls

The number of floors of the buildings varies between four and seven. Due to the changes in the regulations, the height limit was modified during the years, and so additional storeys at the upper levels were constructed. Regarding the position of the buildings, two groups can be distinguished: buildings in the middle of the block (rectangular shape) and chamfer buildings in the corner of the urban block (pentagonal shape). The ground floor of these buildings has a higher height than any other level since it was intended for commercial use and required a more versatile space. 
The configuration of Eixample's buildings can be described by some typical characteristics such as the position and number of patios (central and lateral, see in Figure 5), the position and size of the staircase box, the number of walls (parallel to the facades and parallel to the lateral walls), the distance between walls, etc. The size and position of the openings is another important parameter being a source of seismic vulnerability.

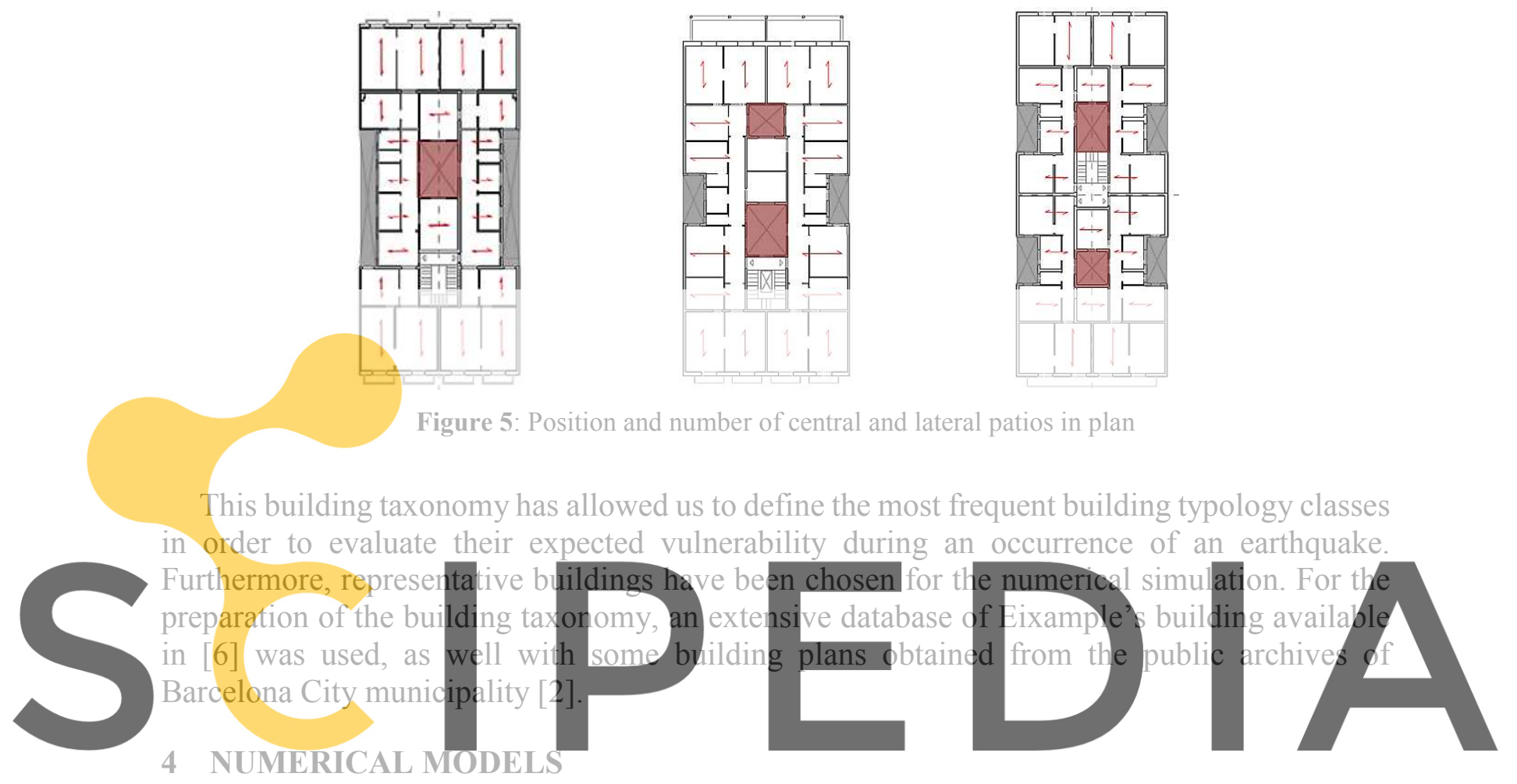

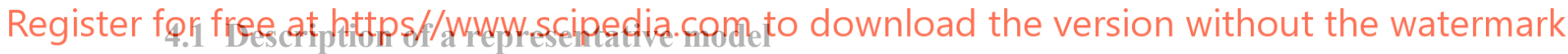

This section investigates the seismic performance of a representative building typology from

Eixample district. Focus is given on a selection of structural characteristics identified by the building taxonomy. The performance of the representative building typology has been compared with that of a reference regular unreinforced masonry structure. This comparison aims to provide insight into the influence of the structural features of the building typology on its seismic performance.

Eixample blocks are formed by a series of individual buildings, having their lateral walls in contact with each other (see Figure 1). The representative building of the studied structural typology is composed of 5 floors and has an internal patio at its middle and two semi-patios at the two lateral sides (Figure 6). In this work, the building has been studied as isolated without considering any interaction with neighbouring structures, which will be the focus of future work. The load-bearing system consists of two main parallel façade walls with two perpendicular lateral walls. The thickness of the facade walls is $0.30 \mathrm{~m}$, and that of the lateral ones is $0.15 \mathrm{~m}$. Also, the representative model has interior walls parallel to the façade with a thickness of $0.15 \mathrm{~m}$. The dimensions of the representative model are $14 \times 22 \mathrm{~m}^{2}$ in plan. The total height of the building is $16 \mathrm{~m}$. A common feature of Eixample buildings is that the height 
of the ground floor is higher than the rest of them. Therefore, the ground floor is $4 \mathrm{~m}$ high while the rest of the storeys are $3 \mathrm{~m}$ high. The load capacity of the load-bearing walls is very much affected by the presence of several openings. The façade has 19 openings with considerable size, which results in an area of approximately $32 \%$ of the façade. The ground floor is used for commercial activities, and thus the configuration of the openings at this part of the façade walls is different, as shown in Figure 6. Due to the presence of larger openings, steel beams have been used to model the lintels above all the doors and windows.

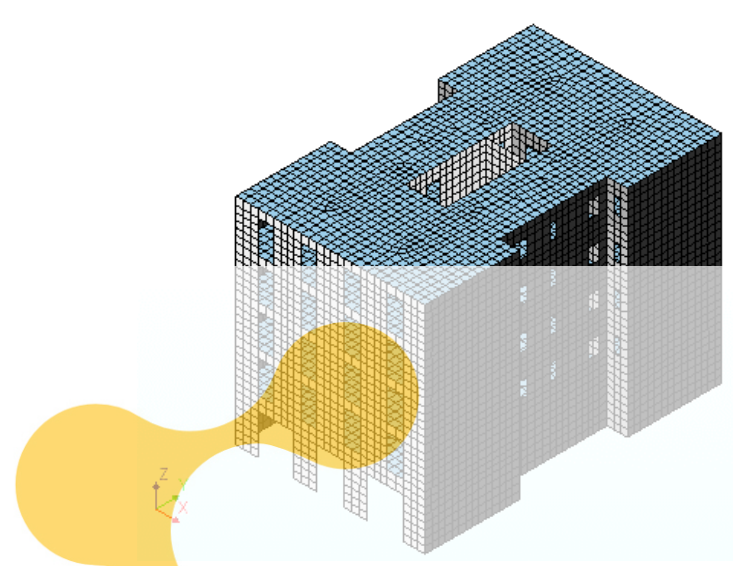

a)

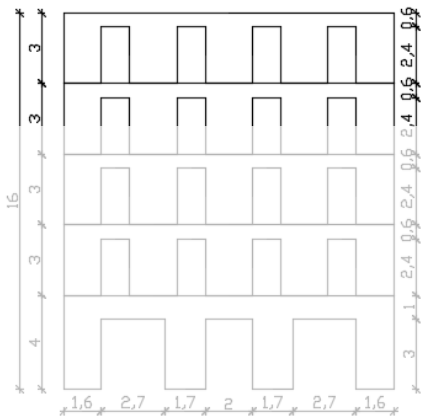

b)

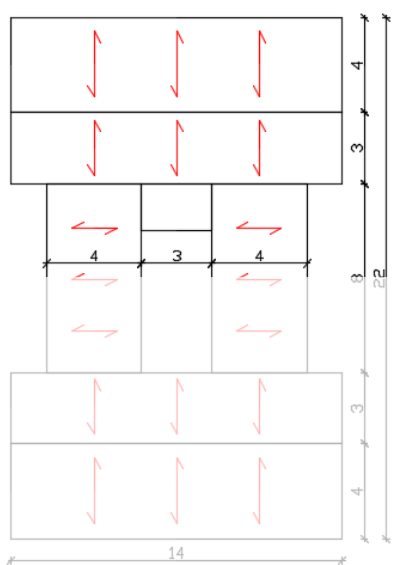

c)

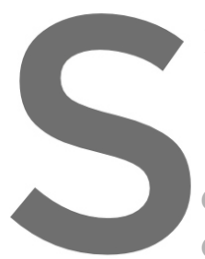

Figure 6: The representat

The reference mode

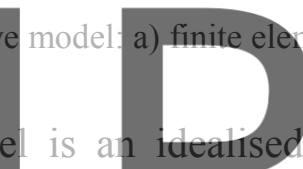

dimensions of $8.9 \times 22 \mathrm{~m}$

and a total height of

of the facade openings has been assumed, as
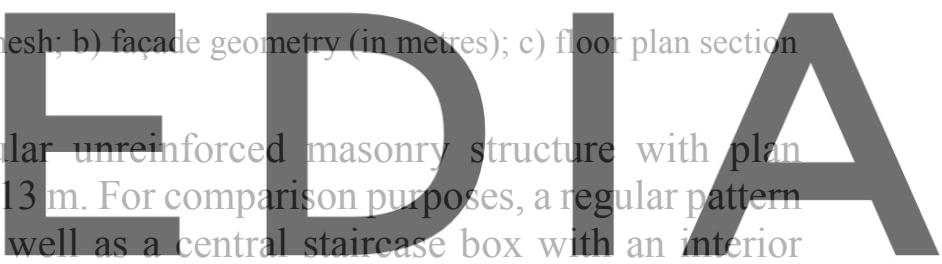

patio. Figure 7 illustrates a general view of the model with the dimensions of the plan and façade

Register fornficesat https//www.scipedia.com to download the version without the watermark

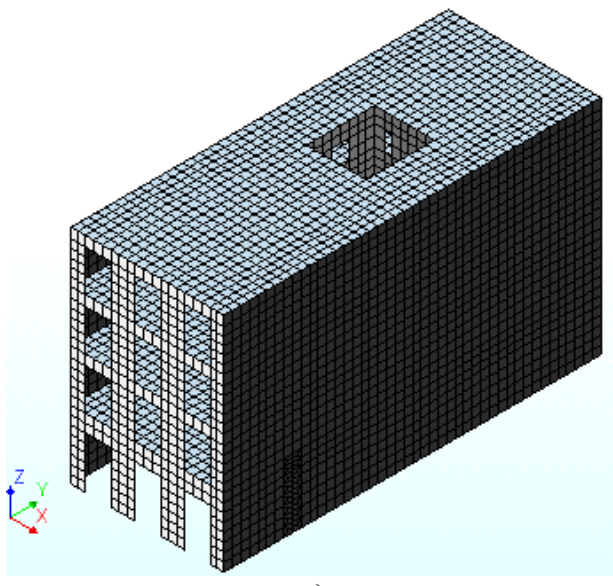

a)

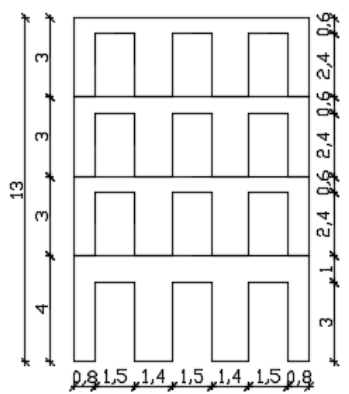

b)

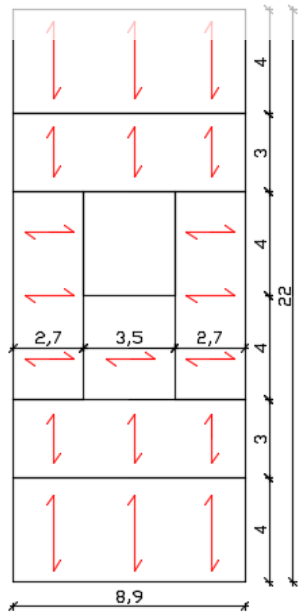

c)

Figure 7: The reference model: a) finite element mesh; b) façade geometry (in metres); c) floor plan section 
The finite element models have been prepared and analysed using the software DIANA-FEA 10.3 [7]. Curved shell (quadrilateral CQ40S type) elements have been used for the walls and floors of the buildings. This element is defined by eight nodes and five degrees of freedom for each node. An in-plane Gauss integration scheme has been chosen with $3 \times 3$ integration points on the faces, and a Simpson integration scheme with seven points through the thickness of the elements. The beam element CL18B has been used for the steel lintels, composed of three nodes and six degrees of freedom at each of them.

The total number of nodes and elements of the idealised model is 26545 and 8927 , respectively. The representative model is composed of 13646 quadrilateral curved shell elements, 664 beam elements and 2390 one-node translational mass elements to provide the load over the unidirectional flexible diaphragms. The final mesh has been selected after performing a series of sensitivity analyses on mesh sizes. The average element size is $0.5 \mathrm{~m}$. The base of the building has been considered fixed to the ground by restricting both translational and rotational movements. All the analyses have considered mechanical and geometrical nonlinear behaviour.

\subsection{Material properties}

Table 1 and Table 2 summarize the mechanical parameters and gravity loads adopted in the numerical model.
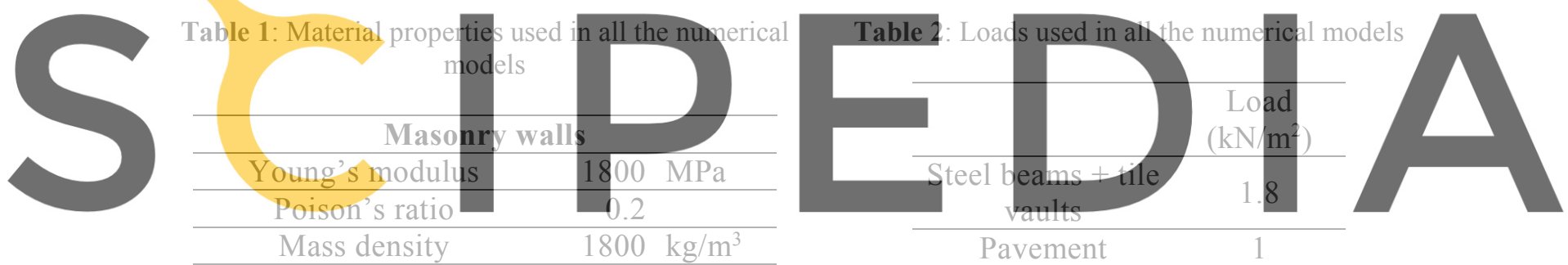

Register for freenarte \$tepstyngthw.scipedia.tom to downloadithervenslion without the watermark Compressive fracture energy

\begin{tabular}{|c|c|c|}
\hline Tensile strength & 0.08 & $\mathrm{MPa}$ \\
\hline Tensile fracture energy & 50 & $\mathrm{~N} / \mathrm{m}$ \\
\hline \multicolumn{3}{|c|}{ Flexible floors } \\
\hline Young's modulus $\mathrm{E}_{\mathrm{x}}$ & 1100 & $\mathrm{MPa}$ \\
\hline Young's modulus $\mathrm{E}_{\mathrm{y}}$ & 7000 & $\mathrm{MPa}$ \\
\hline Young's modulus $\mathrm{E}_{\mathrm{z}}$ & 1100 & $\mathrm{MPa}$ \\
\hline Poison's ratio & 0.06 & \\
\hline Poison's ratio & 0.38 & \\
\hline Poison's ratio & 0.15 & \\
\hline Shear modulus $\mathrm{G}_{\mathrm{xy}}$ & 450 & $\mathrm{MPa}$ \\
\hline Shear modulus $\mathrm{G}_{\mathrm{yz}}$ & 450 & $\mathrm{MPa}$ \\
\hline Shear modulus $\mathrm{G}_{\mathrm{xz}}$ & 450 & $\mathrm{MPa}$ \\
\hline \multicolumn{3}{|c|}{ Steel beams } \\
\hline Young's modulus & 210000 & $\mathrm{MPa}$ \\
\hline Poison's ratio & 0.3 & \\
\hline Mass density & 7850 & $\mathrm{~kg} / \mathrm{m}^{3}$ \\
\hline
\end{tabular}

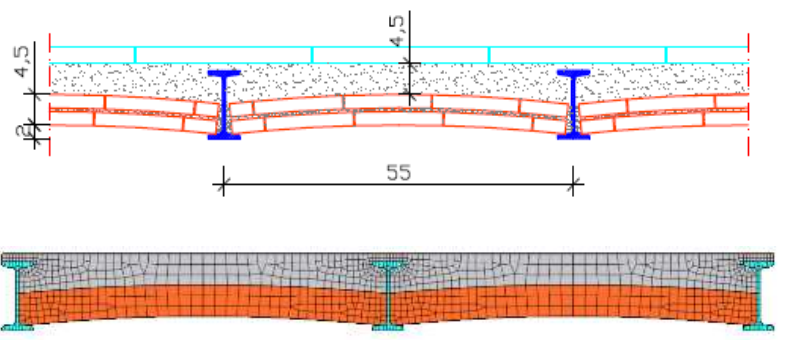

Figure 8 - Flexible diaphragm system of tile vaults with steel beams 
The mechanical masonry properties as the compressive strength and Young's modulus are based on some experimental tests done on specimens extracted from some buildings in Barcelona [8]. The values are within the range of the proposed ones for solid brick masonry in the Italian code [9]. The nonlinear physical behaviour of the masonry walls has been defined through the total strain fixed crack model detailed in DIANA-FEA [7]. This constitutive model considers a parabolic softening curve under compression and an exponential one under tension.

The floors have been modelled as unidirectional flexible diaphragms assuming a linear orthotropic material. The elastic properties for the floors were obtained from a 3D numerical model with steel beams and tile vaults (Figure 8). The Young's modulus in both X and Y directions (perpendicular and parallel to the beams), as well as the shear modulus, have been calculated through in-plane nonlinear analysis of the floor system. The connections between the different materials in the floor system has been assumed perfect, without including any interfaces. Table 2 shows the loads considered that have been applied as mass to the nodes of the floors (considering the distribution for one-way slab diaphragms).

\section{PUSHOVER ANALYSIS}

The pushover analysis is a nonlinear static analysis that aims at simulating the structural response of the investigated building during a seismic action with the application of a monotonically increasing lateral load pattern [10]. The response of the structure is given by the

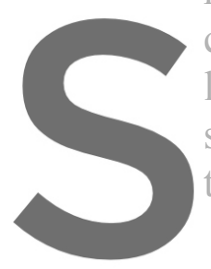
capacity curve, which represents the building's lateral load res
lateral displacement. Despite its limitations, pushover analy
seismic capacity and the expected dandage, as well as identify
the structure [1 1$]$.
The horizontal loads have been applied by adopting a mass
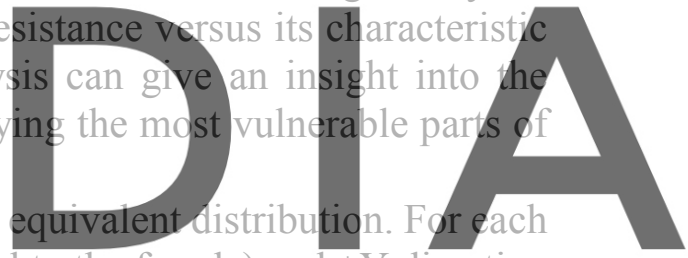
analysed case, pushover analyses in both $+X$ direction (parallel to the façade) and $+Y$ direction applied in the first stage of the analysis, and then horizontal seismic forces proportional to the mass of the structure have been applied incrementally until the analysis stops due to nonconvergence. A Newton-Raphson regular procedure has been used along considering an arclength for solving the nonlinear system of algebraic equations. The convergence has been checked using energy criteria with a convergence tolerance of 0.001 .
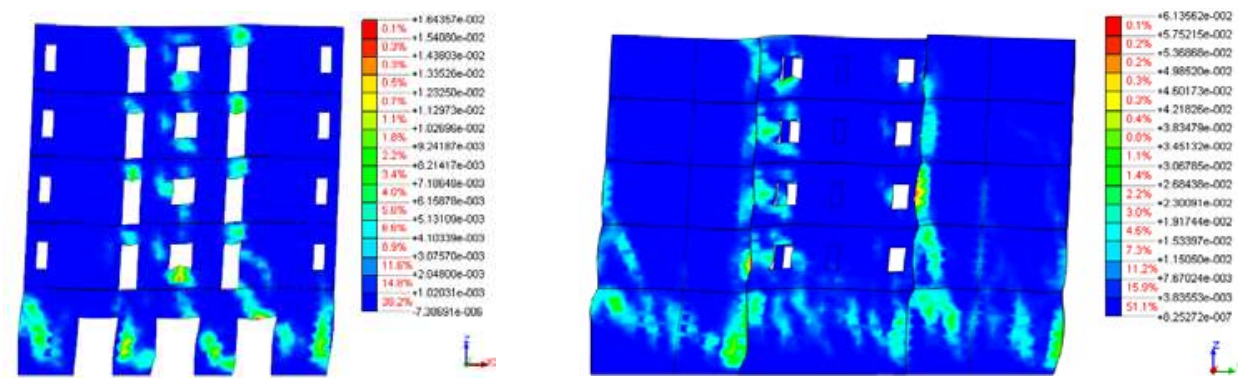

Figure 9: Contour of principal tensile strains: interior wall parallel to the facade for a pushover in $+\mathrm{X}$ direction (left) and the lateral walls for a pushover in $+Y$ direction (right) 
As can be seen from Figure 9, the formation of the cracks (identified using a contour of the maximum principal strains) is located at the load-bearing walls (parallel to the action of the force). The first cracks are formed around the openings on the façade and the interior walls, as the seismic action is applied in the $+X$ direction. Diagonal shear cracks appear on the interior walls parallel to the facade in the direction of the seismic action, while vertical cracks develop above the openings due to bending of the spandrels. For the pushover analysis in $+Y$ direction, the lateral walls start to present damage with shear cracks starting from the lower floor level and progressing throughout the walls.

Regarding the pushover analysis in the direction parallel to the façade $(+X)$, first, the shear cracks appear on the walls of the ground floor, causing a local out-of-plane mechanism of the perpendicular lateral wall. After the continued opening of these cracks, the collapse of the structure happens as a result of the shear failure of the interior walls on the ground floor. This mechanism is caused by the presence of bigger openings in these walls. In the other direction $(+Y)$, the collapse mechanism is due to the shear failure of the lateral load-bearing walls. The lateral patios present discontinuity of the lateral walls and thus decreases the capacity of the structure.

\section{Figure 10 presents pushover capacity curves in terms of horizontal acceleration against} horizontal displacement at the roof level. The difference in the seismic capacity of the buildings is $5 \%$ and $40 \%$ for the pushover analyses in $+\mathrm{X}$ and $+\mathrm{Y}$ directions, respectively. The response of the building in the $+\mathrm{X}$ direction (parallel to the façade) differs significantly from the response

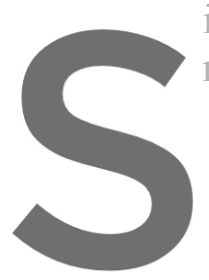
in the $+\mathrm{Y}$ direction (perpendicular to the façade

\section{more flexible due to t}
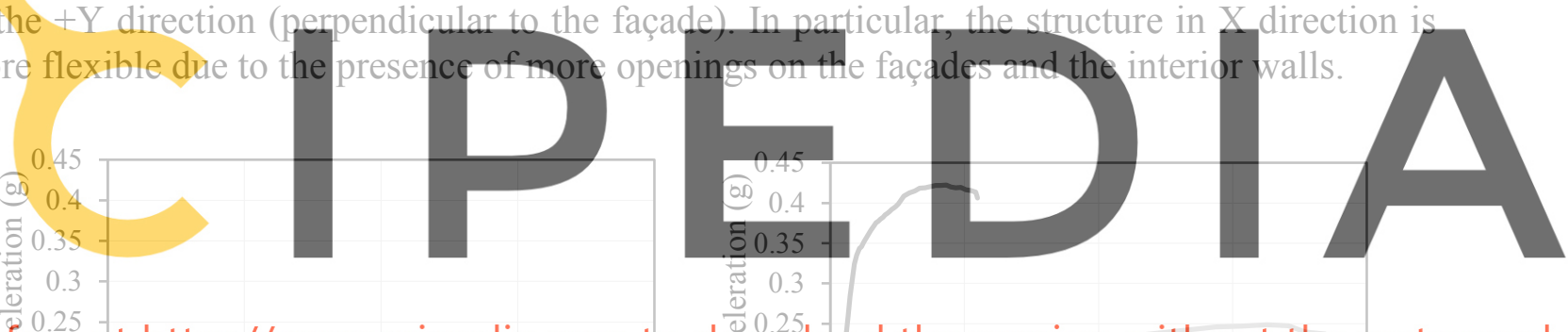

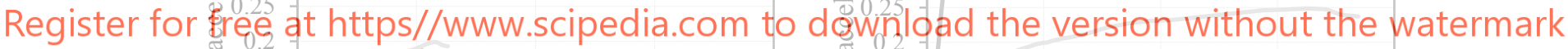
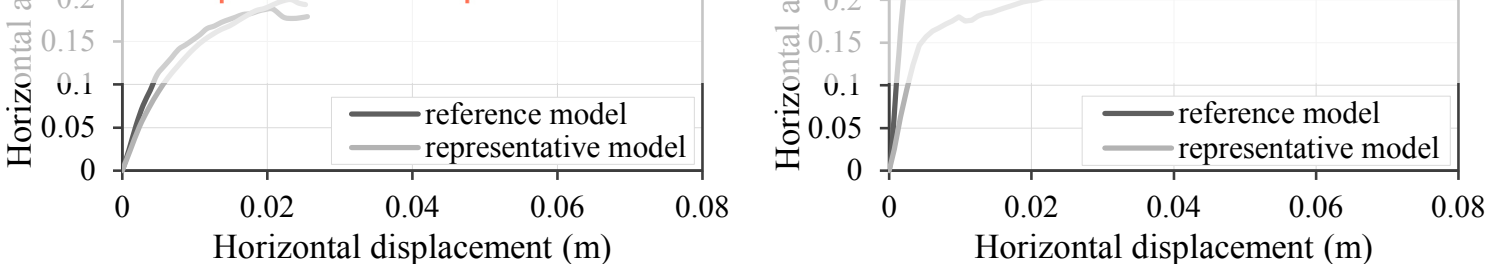

Figure 10: Capacity curves of the representative and the reference model: pushover $+X$ direction (left) and pushover + Y direction (right)

As it was mentioned previously, the representative model considers some typical characteristics and heterogeneities of the presented building taxonomy. Thus, it presents a distinctive seismic behaviour than the one of the reference model. This is due to the differences in the width and height of the buildings, and the changes in the size of the openings on the ground floor. As a comparison with the reference model, the seismic capacity of the representative building is much different in the $+Y$ direction as a result of the presence of the lateral patios. This building typology shows lower capacity in the $+Y$ direction, but it presents higher displacements in the direction perpendicular to the façade. 
Parametric analysis has been carried out to evaluate the different seismic response of the representative building by adding more storeys in height (changing the total height of the building). Figure 11 illustrates the capacity curves from the parametric analysis.
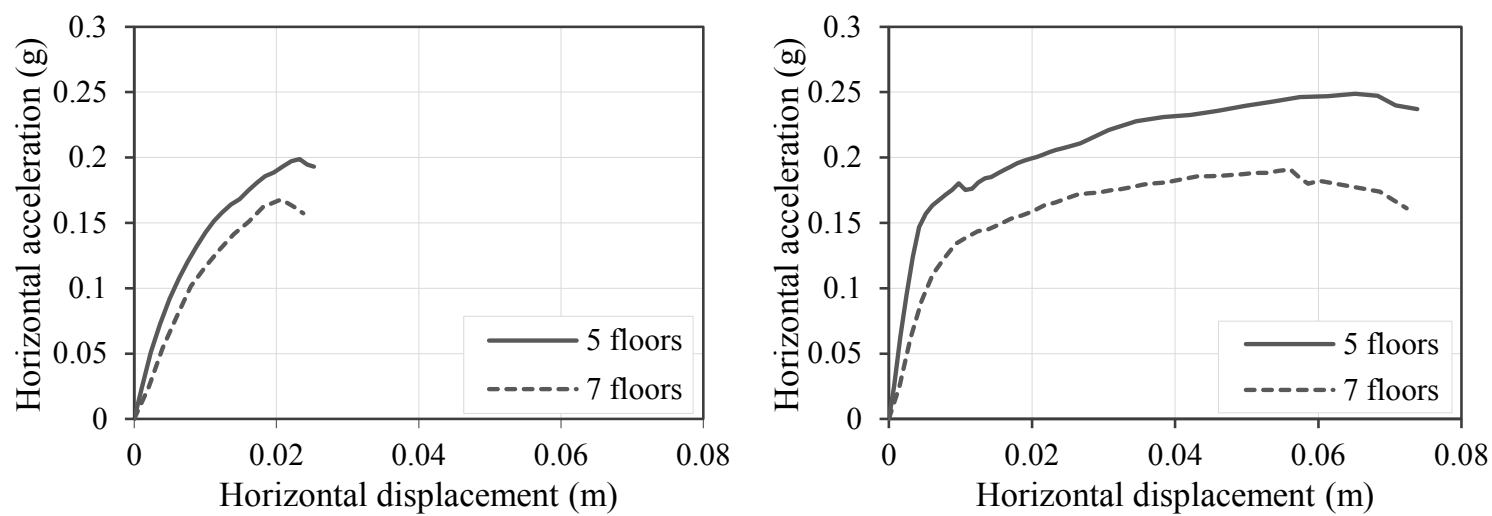

Figure 11: Parametric analysis - addition of floors in the representative building: pushover in $+X$ direction (left) and $+Y$ direction (right)

The results of the parametric analysis related to the addition of floors to the representative building demonstrate the influence of the total height in the seismic response of this typology. As anticipated, the seismic capacity of the higher buildings is decreased and they are more vulnerable. It can be observed a difference of $20 \%$ between the capacity of the models of 5 and 7 floors in the direction perpendicular to the façade $(+Y)$. The height is one of the many parameters mentioned in the building taxonomy that are an apparent source of vulnerability regarding these typical unreinforced masonry buildings.

\section{CONCLUSIONS}

The results of this preliminary study can be summarized in the following:

- A detailed building taxonomy, considering all the parameters that may influence on the seismic vulnerability, is a necessary step for the purpose of selecting representative buildings and variants to be analysed into more detail by means of numerical methods.

- The numerical models can aid to a better understanding of the seismic performance of representative buildings. Certain structural irregularities may produce a significant increase of the seismic vulnerability. Among these are the presence of big openings on the ground floor, central and lateral patios and different height levels.

- $\quad$ The analysed cases showed a typical shear failure with diagonal cracking in walls parallel to the action of the earthquake equivalent loads. Comparisons were made among different models by varying some structural parameters. The numerical results afforded satisfactory predictions of seismic response and the influence of the building's structural characteristics.

- Future works will focus on the investigation of the influence on the seismic performance of other heterogeneities or irregularities not yet considered in the analyses but identified as relevant in the building taxonomy. 
Acknowledgements. The authors gratefully acknowledge the financial support from the Ministry of Science, Innovation and Universities (MCIU) of the Spanish Government, the State Agency of Research (AEI) and the European Regional Development Fund (ERDF) through the SEVERUS project (Multilevel evaluation of seismic vulnerability and risk mitigation of masonry buildings in resilient historical urban centres, ref. num. RTI2018099589-B-I00). The support from Secretaria d'Universitats i Investigació de la Generalitat de Catalunya through a pre-doctoral grant awarded to the first author is also gratefully acknowledged.

\section{REFERENCES}

[1] Pelà, L. New Trends and Challenges in Large-Scale and Urban Assessment of Seismic Risk in Historical Centres. Int. J. Archit. Herit. (2018) 12:1051-1054.

[2] Cara, S., Aprile, A., Pelà, L. and Roca, P. Seismic Risk Assessment and Mitigation at Emergency Limit Condition of Historical Buildings along Strategic Urban Roadways. Application to the "Antiga Esquerra de L'Eixample" Neighborhood of Barcelona. Int. J. Archit. Herit. (2018) 12: 1055-1075.

[3] Paricio Casademunt, A. Secrets d'un sistema constructiu: 1'Eixample. Barcelona: Edicions UPC (2001) [in Catalan].

[4] Lantada, N., Pujades, L.G. and Barbat, A.H. Vulnerability index and capacity spectrum based methods for urban seismic risk evaluation. A comparison. Natural Hazards (2009) 51:501-524.

[5] Pujades, L.G., Barbat, A.H., González-Drigo, J.R., Avila, J. and Lagomarsino, S. Seismic performance of a block of buildings representative of the typical construction in the Eixample district in Barcelona (Spain). Bull. Earthq. Eng. (2012) 10:331-349.

[6] Cornadó Bardón, C. Comportament mecánic-estructural dels edificis històrics de murs d'obra de fàbrica de maó de l'Eixample de Barcelona. Tesis doctoral UPC, Barcelona, (2015) [in Catalan].

[7] TNO DIsplacement method ANAlyser (DIANA FEA), release 10.3, Delft, Netherlands (2019).

[8] Segura, J., Pelà, L., Roca, P. and Cabané, A. Experimental analysis of the size effect on the compressive behaviour of cylindrical samples core-drilled from existing brick masonry. Construction and building materials (2018) 228:116759.

[9] Italian code - Italian Ministry of Infrastructure and Transport. Circolare 21 Gennaio 2019. Istruzioni per l'applicazione delle nuove norme tecniche per le costruzioni, (2019) [in Italian].

[10] Endo, Y., Pelà, L. and Roca, P. Review of Different Pushover Analysis Methods Applied to Masonry Buildings and Comparison with Nonlinear Dynamic Analysis. Earthq. Eng. (2017a) 21:1234-1255.

[11] Saloustros, S., Pelà, L., Contrafatto, F.R., Roca, P. and Petromichelakis, I. Analytical Derivation of Seismic Fragility Curves for Historical Masonry Structures Based on Stochastic Analysis of Uncertain Material Parameters. Int. J. Archit. Herit. (2019) 13 (7):1142-64. 